blood-air interface. ${ }^{1}$ Inasmuch as this response affects coagulation, it probably contributes to the perioperative fall in hemoglobin. ${ }^{2}$

The MECC circuit has a very short tubing length with elimination of the venous reservoir and avoids the conventional cardiotomy suction. As a result, there is a lower priming volume and reduced hemodilution compared with conventional cardiopulmonary circuits ${ }^{3}$ and probably less initiation of the inflammatory response.

Patients undergoing bypass surgery on MECC systems have 30-day mortalities comparable with those of patients treated with conventional bypass circuits. ${ }^{4}$ Studies have also repeatedly demonstrated a decreased requirement for blood transfusions. ${ }^{4}$ In our patients, the postoperative hemoglobin concentration remained higher than our standard transfusion trigger $(8.0 \mathrm{~g} / \mathrm{dL})$ and was consistent with previous studies ${ }^{4,5}$ (Table 1). MECC also allows for complete revascularization on a still heart and bloodless field and in our experience is technically less demanding than off-pump surgery.

The reduced priming volume of the MECC system results in less hemodilution and maintains a near normal hematocrit during the CPB process. This technique contributes significantly to the avoidance of blood transfusion in this subgroup of patients. We have successfully used this technique in our institution for coronary artery bypass surgery and more recently for aortic valve surgery, and we consider the MECC procedure a useful tool in the armamentarium for Jehovah's Witnesses undergoing cardiac surgery. As the evidence for the adverse consequences of homologous blood transfusion mounts, we should consider treating all of our patients with fully heparin-coated circuits, low priming volumes, and meticulous surgical hemostasis as in our Jehovah Witness patients.

We are grateful to Gerry Webb for his assistance in the study.

\section{References}

1. Aldea GS, Soltow LO, Chandler WL, Triggs CM, Vocelka CR, Crockett GI, et al. Limitation of thrombin generation, platelet activation, and inflammation by elimination of cardiotomy suction in patients undergoing coronary artery bypass grafting treated with heparin-bonded circuits. J Thorac Cardiovasc Surg. 2002;123: 742-55.

2. Royston D. The inflammatory response and extracorporeal circulation. J Cardio thorac Vasc Anesth. 1997;11:341-54.

3. Fromes Y, Gaillard D, Ponzio O, Chauffert M, Gerhardt MF, Deleuze P, et al Reduction of the inflammatory response following coronary bypass grafting with total minimal extracorporeal circulation. Eur J Cardiothorac Surg. 2002;22: 527-33.

4. Remadi JP, Rakotoarivelo Z, Marticho P, Benamar A. Prospective randomized study comparing coronary artery bypass grafting with the new mini-extracorporeal circulation Jostra system or with a standard cardiopulmonary bypass. Am Heart J. 2006;151:198.

5. Mueller XM, Jegger D, Augstburger M, Horisberger J, Godar G, von Segesser LK A new concept of integrated cardiopulmonary bypass circuit. Eur J Cardiothorac Surg. 2002;21:840-6.

\title{
Use of the hybrid operating room for aortic valve replacement in a patient with anomalous left circumflex artery
}

\author{
Ramanan Umakanthan, MD, Zachary E. Brewer, BS, John G. Byrne, MD, and Rashid M. Ahmad, MD, \\ Nashville, Tenn
}

Preoperative detection of anomalous coronary artery anatomy and clear delineation of its anatomic course are essential in patients undergoing aortic valve surgery so that the surgical technique can be modified to avoid coronary vessel injury. We present the case of aortic valve replacement (AVR) in a patient who was discovered to have an aberrant left circumflex artery (LCX) on coronary angiographic

\footnotetext{
From the Vanderbilt Heart \& Vascular Institute, Nashville, Tenn

Disclosures: None.

Received for publication April 2, 2009; revisions received April 22, 2009; accepted for publication April 30, 2009; available ahead of print July 6, 2009.

Address for reprints: Rashid M. Ahmad, MD, Vanderbilt Heart \& Vascular Institute,

1215 21st Ave South, Nashville, TN 37232-8802 (E-mail: rashid.ahmad@

vanderbilt.edu)

J Thorac Cardiovasc Surg 2010;139:e123-5

$0022-5223 / \$ 36.00$

Copyright (C) 2010 by The American Association for Thoracic Surgery

doi:10.1016/j.jtcvs.2009.04.048
}

analysis. We present a new surgical approach for AVR in the setting of an anomalous LCX.

\section{CLINICAL SUMMARY}

A 51-year-old man with a history of aortic stenosis, progressively worsening dyspnea, and an abnormal stress test result was referred to the Vanderbilt Heart Institute for AVR. Transesophageal echocardiographic analysis had revealed an aortic valve area of $0.75 \mathrm{~cm}^{2}$ and an ejection fraction of $65 \%$ to $70 \%$. Preoperative coronary angiographic analysis revealed no significant atherosclerotic disease but demonstrated an anomalous LCX that originated from a separate ostium adjacent to the ostium of the right coronary artery and coursed behind the aortic annulus. Computed tomographic angiographic analysis confirmed the retroaortic course of the LCX. 
A sternotomy was performed, and the pericardium was opened. Arterial cannulation was performed through the ascending aorta, and venous cannulation was performed through the right atrium. The aorta was crossclamped, and cold blood cardioplegia was administered.

An aortotomy was performed with a J-type incision extending above the annulus of the noncoronary cusp. On examination, the aortic valve was bicuspid with densely calcified leaflets. The leaflets were excised, and calcifications along the annulus were carefully removed. The LCX was found to originate adjacent to the ostium of the right coronary artery and course in a retroaortic direction close to the annulus. It was believed that the best way to avoid damaging the artery would be to tilt the valve superiorly and above the annulus of the noncoronary cusp. Prolene sutures were placed up to the commissure of the noncoronary and right coronary cusps. A 27-mm St Jude Regent mechanical valve (St Jude Medical, St Paul, Minn) was placed. The sutures were tied down on the left and right sides in a standard fashion. On the noncoronary cusp side, horizontal mattress sutures were placed through the sewing ring and brought outside the aorta, and these sutures were tied over a pledget (Figure 1). The aortotomy was closed, and the patient was weaned from cardiopulmonary bypass. Intraoperative transesophageal echocardiographic analysis revealed that the valve was well seated and that the postoperative ejection fraction was normal. The sternotomy was closed, and completion coronary angiographic analysis confirmed the integrity of the anomalous LCX (Figure 2). The patient did well postoperatively and was discharged home on the fifth postoperative day.

\section{DISCUSSION}

Unidentified anomalous LCX anatomy for a patient undergoing AVR can have detrimental consequences, resulting in arrhythmia, bleeding, myocardial infarction, and mitral regurgitation. ${ }^{1}$ Additionally, there have been reports suggesting a congenital association between abnormal origin of coronary arteries and valvular disease, specifically with aberrant LCX coronary arteries that are retroaortic. ${ }^{2}$ Given this association, preoperative coronary angiographic analysis should be performed in all patients undergoing AVR, regardless of age. Flores and Byrne ${ }^{3}$ have described their technique and experience in which preoperative coronary angiographic analysis was invaluable in facilitating surgical planning for AVR in a patient with an anomalous LCX encircling the aortic annulus.

However, detection and mobilization of coronary artery anomalies might not be not sufficient to prevent injury because reports have shown that distortion and subsequent severe intimal damage and thrombotic occlusion of a vessel is still possible if a large-valve prosthesis is inserted and causes compression within the atrioventricular groove. ${ }^{1}$ Hence postoperative imaging remains essential.

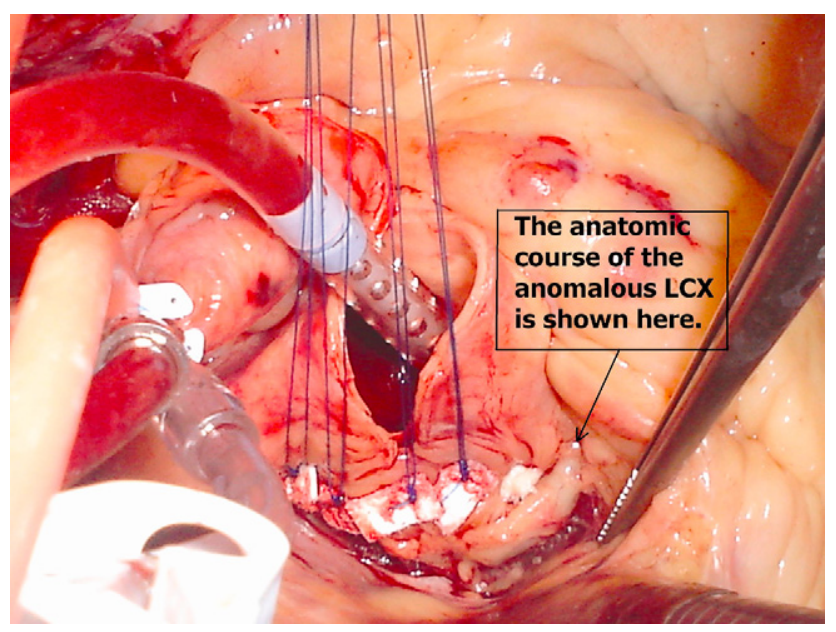

FIGURE 1. Intraoperative image demonstrating sutures placed through the sewing ring, brought outside the aorta, and tied over a pledget. The anatomic course of the anomalous left circumflex artery $(L C X)$ is labeled with the black arrow.

In this case we used our hybrid operating room to perform a modified surgical approach with completion coronary angiographic analysis to ensure postoperative patency of the anomalous LCX. The prosthetic valve was tilted superiorly above the aortic annulus in relationship to the retroaortic path of the artery to prevent stenosis and compression. The hybrid operating room at the Vanderbilt Heart Institute was an ideal environment to perform this procedure because it combines the technology and imaging capabilities of

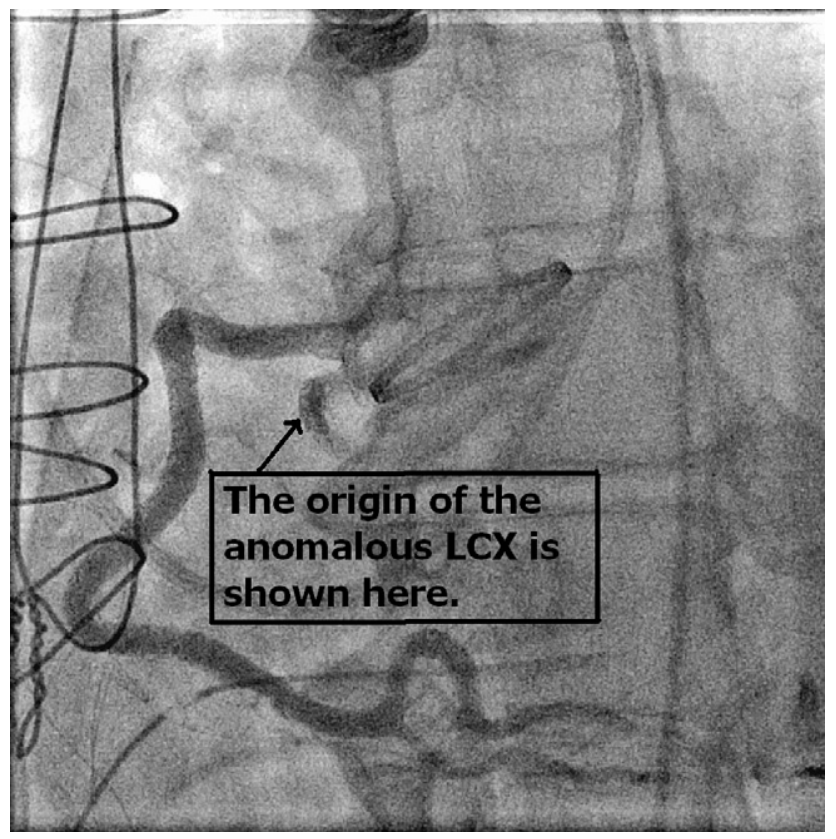

FIGURE 2. Postoperative coronary angiogram demonstrating patency of the anomalous left circumflex artery $(L C X)$ after completion of the procedure. The origin of the anomalous LCX is labeled with the black arrow. 
a cardiac catheterization laboratory with the facilities of a cardiac surgical operating room. ${ }^{4}$ This allowed for immediate postoperative imaging to verify the patency and integrity of the anomalous LCX.

\section{References}

1. Veinot JP, Acharya VC, Bedard P. Compression of anomalous circumflex coronary artery by a prosthetic valve ring. Ann Thorac Surg. 1998;66:2093-4.
2. Chaitman BR, Lespérance J, Saltiel J, Bourassa MG. Clinical, angiographic, and hemodynamic findings in patients with anomalous origin of the coronary arteries. Circulation. 1976;53:122-31

3. Flores RM, Byrne JG. Aortic valve replacement with an anomalous left circumflex coronary artery encircling the aortic anulus. J Thorac Cardiovasc Surg. 2001;121: 396-7.

4. Zhao DX, Leacche M, Balaguer JM, Boudoulas KD, Damp JA, Greelish JP, et al Routine intraoperative completion angiography after coronary artery bypass grafting and 1-stop hybrid revascularization results from a fully integrated hybrid catheterization laboratory/operating room. J Am Coll Cardiol. 2009;53:232-41.

\title{
Successful pediatric single-lung transplantation with previous contralateral pneumonectomy, using controlled "donation after cardiac death" lung, for congenital pulmonary vein stenosis
}

\author{
Amit Pawale, MRCS, ${ }^{\mathrm{a}}$ Michael McKean, MD, FRCPCH,${ }^{\mathrm{b}}$ John Dark, FRCS, ${ }^{\mathrm{a}}$ and Asif Hasan, FRCSCTh, ${ }^{\mathrm{a}}$ \\ Newcastle upon Tyne, United Kingdom
}

\section{CLINICAL SUMMARY}

We report the case of a 10-year-old child who had bilateral congenital pulmonary vein stenosis. He presented for the first time to his local hospital at the age of 4 years with life-threatening hemoptysis and was diagnosed with isolated severe left pulmonary vein stenosis and moderate to severe right upper lobe pulmonary vein stenosis. This was treated with left pneumonectomy. Two years after pneumonectomy, he presented with recurrent hemoptysis and reduced exercise tolerance. During the next 4 years, he underwent sutureless repair of his right pulmonary venous stenosis and multiple balloon dilatations (23). He also had multiple stents placed in these veins. Despite this, he became progressively short of breath and was evaluated for right single-lung transplantation. A 6-minute walk test demonstrated desaturation to $67 \%$ on room air after $245 \mathrm{~m}$. Cardiac catheterization revealed suprasystemic pulmonary pressure. His forced expiratory volume in 1 second was $43 \%$ predicted and height was $126 \mathrm{~cm}$. The computed tomography pulmonary angiogram is shown in Figure 1. We performed a right single-lung transplant using a donation after cardiac death (DCD) lung. The donor was a 13-year-old boy who died of irreversible anoxic cerebral damage after traumatic

\footnotetext{
From the Department of Cardiothoracic Surgery and Transplantation, ${ }^{\mathrm{a}}$ Pediatric Respiratory Medicine, ${ }^{\mathrm{b}}$ Freeman Hospital, Newcastle upon Tyne, United Kingdom. Disclosures: None.

Received for publication Dec 31, 2008; revisions received April 25, 2009; accepted for publication June 4, 2009; available ahead of print Aug 26, 2009.

Address for reprints: Amit Pawale, MRCS, Department of Cardiothoracic Surgery, Freeman Hospital, Newcastle upon Tyne NE7 7DN, United Kingdom (E-mail: amitpawale@doctors.org.uk).

J Thorac Cardiovasc Surg 2010;139:e125-6

$0022-5223 / \$ 36.00$

Copyright (C) 2010 by The American Association for Thoracic Surgery

doi:10.1016/j.jtcvs.2009.06.006
}

asphyxiation. Asystole occurred 15 minutes after withdrawal from ventilation. Eleven minutes later, the lungs were inflated; 6 minutes after this, cold flush preservation was started. The warm uninflated time was 11 minutes, and warm inflated time was 6 minutes. The total warm ischemic time was 17 minutes.

The approach was through a re-do median sternotomy. In addition to severe adhesions, the anatomy was distorted because of a hyperinflated right lung. Cardiopulmonary bypass was established via the right atrium and ascending aorta. The heart was stopped to facilitate the removal of multiple stents incorporated in the left atrial wall. Some deeply

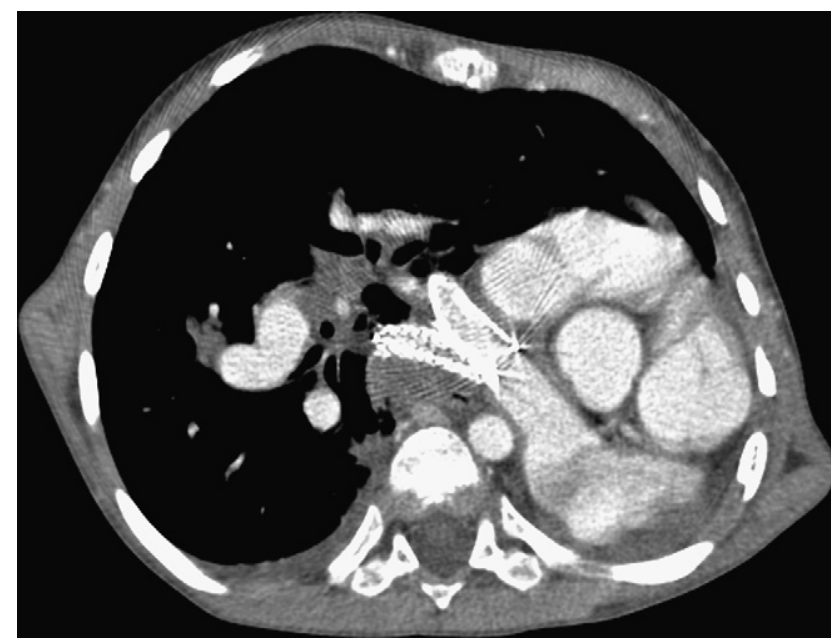

FIGURE 1. Preoperative computed tomography pulmonary angiogram showing previous left pneumonectomy, complete shift of mediastinum to the left and compensatory hyperinflation of the right lung, and patent right upper and lower lobe pulmonary vein stents with stenosis of veins immediately peripheral to them. 